Article

\title{
Fostering Residential Demand Response through Dynamic Pricing Schemes: A Behavioural Review of Smart Grid Pilots in Europe
}

\author{
Kris Kessels ${ }^{1}$, Carolien Kraan ${ }^{2}$, Ludwig Karg ${ }^{3}$, Simone Maggiore ${ }^{4}$, Pieter Valkering ${ }^{1}$ \\ and Erik Laes $1, *$ \\ 1 VITO (Vlaamse Instelling voor Technologisch Onderzoek)/Energyville, Boeretang 200, 2400 Mol, Belgium; \\ Kris.Kessels@vito.be (K.K.); Pieter.Valkering@vito.be (P.V.) \\ 2 ECN (Energieonderzoek Centrum Nederland), Westerduinweg 3, 1755 ZG Petten, The Netherlands; \\ kraan@ecn.nl \\ 3 BAUM Consult GmbH, Gotzinger Straße 48/50, 81371 München, Germany; 1.karg@baumgroup.de \\ 4 RSE SpA, Via Rubattino 54, 20134 Milan, Italy; simone.maggiore@rse-web.it \\ * Correspondence: Erik.Laes@vito.be; Tel.: +32-14-335-909
}

Academic Editor: Shuhui Li

Received: 15 July 2016; Accepted: 7 September 2016; Published: 11 September 2016

\begin{abstract}
Many smart grid projects make use of dynamic pricing schemes aimed to motivate consumers to shift and/or decrease energy use. Based upon existing literature and analyses of current smart grid projects, this survey paper presents key lessons on how to encourage households to adjust energy end use by means of dynamic tariffs. The paper identifies four key hypotheses related to fostering demand response through dynamic tariff schemes and examines whether these hypotheses can be accepted or rejected based on a review of published findings from a range of European pilot projects. We conclude that dynamic pricing schemes have the power to adjust energy consumption behavior within households. In order to work effectively, the dynamic tariff should be simple to understand for the end users, with timely notifications of price changes, a considerable effect on their energy bill and, if the tariff is more complex, the burden for the consumer could be eased by introducing automated control. Although sometimes the mere introduction of a dynamic tariff has proven to be effective, often the success of the pricing scheme depends also on other factors influencing the behavior of end users. An important condition to make dynamic tariffs work is that the end users should be engaged with them.
\end{abstract}

Keywords: dynamic pricing; demand response; smart grid; consumer engagement

\section{Introduction}

A couple of years ago, Faruqui et al. [1] came to the conclusion that only a widespread adoption of dynamic tariffs in the European Union (EU) would tilt the cost-benefit balance of the investment in advanced metering infrastructure (AMI) towards a net benefit for society. Such dynamic tariffs come in many forms (cf. Section 2.1), but they all share the general characteristic that they aim for a better reflection of the actual (time-of-use dependent) costs of electricity provision. Giordano and Fulli [2] describe in more detail how AMI could be the key enabling technology for the establishment of new business platforms offering tailored energy services to households. Active energy end-use management through dynamic tariffs could be one of the attractive business offerings of the future for households. Today however, the tariff structure of most households in the EU is still not related to the timing of energy usage (except for day and night tariffs) or the overall level of energy consumption. By failing to reflect the real cost of electricity provision, the current tariff structures also fail to stimulate flexibility in energy demand, and hence to realize system-level benefits in terms of e.g., lowering investments in 
peak power plants, better grid management, or better integration of intermittent renewable electricity generation [3,4]. In addition, the adoption of dynamic tariffs is challenging from the perspective of the households involved, because of the time sensitivity of many household practices (e.g., cooking, doing the laundry, heating and cooling, etc.). More generally, system-level benefits of introducing dynamic tariffs must be aligned with the interests of several stakeholders involved in the energy system (transmission system operators, distribution system operators, generators, electricity retailers, and end users) [5].

Although a variety of dynamic pricing schemes have been piloted in demand response projects or programs all over Europe, differences are more numerous than commonalities and there is still a need for drawing useful lessons on how AMI in conjunction with dynamic tariffs could help in engaging households in energy system management by reducing overall energy consumption and/or shifting loads. This survey paper sheds additional light on some of the issues involved, without claiming to give the final answer on many of the complexities involved. To this end, it first presents key lessons learned from a set of meta-reviews assessing the effectiveness of various pricing schemes, and on literature zooming in on the motivations of households to change their energy demand by means of dynamic pricing. These lessons will be compared with current experiences in a set of demand response projects which have been analyzed within the framework of the "Smart Consumer, Smart Customer, Smart Citizen" (S3C) project (The European Community's Seventh Framework Programme funded project S3C ("Smart Consumer, Smart Customer, Smart Citizen") analyzes new options deriving from smart grid technologies for the activation and long-term engagement of end users (for more information, see the project website <www.s3c-project.eu $>$ ). End-user engagement through various tools, such as different set-ups made of incentives, intelligent devices and feedback information, is analyzed and related to the energy end users' behavioural response.).

The paper is structured as follows. Section 2 defines the key terms used in this paper and introduces the key attributes of dynamic tariffs. In addition, Section 2 contains a literature survey on how to stimulate demand response by means of dynamic tariffs, and derives from this survey four distinct hypotheses for further testing in our case research. Section 3 discusses the case-study methodology used to analyze demand response to various dynamic tariff schemes in our selection of European pilot projects. Section 4 compares these findings from literature with the results of our in-depth analysis of the case studies within the S3C project. The significance of the findings is discussed in Section 5 and conclusions are formulated in Section 6.

\section{Theoretical Background}

In this section, we discuss the conceptual framework for analysis. We first define the key terms in our analysis by giving an in-depth characterization of the different attributes of dynamic pricing schemes (Section 2.1). Section 2.2 introduces the main findings of a literature survey on the effects of dynamic pricing on households.

\subsection{Definitions and Attributes of Dynamic Pricing Schemes}

Demand response (DR) programs can be considered as a subset of demand-side management (DSM) programs that rely on price signals as main incentives for altering patterns of electricity usage, which may involve time shifting and/or load reduction [5,6]. The pricing schemes implemented in the context of DR range from simple time-of-use (TOU) tariffs to more complex and dynamic set-ups such as real-time pricing (RTP). Within TOU pricing schemes, prices are mostly fixed in advance for a long period and have fixed time blocks, whereas RTP typically exhibit a greater variability as prices fluctuate in response to external variables, e.g., hourly market prices. Due to its high stability, TOU pricing is sometimes not regarded as a dynamic pricing scheme [7]. Nevertheless, in the present paper we use the term dynamic pricing as an umbrella terms covering the range from the more stable TOU tariffs to the more changing RTP. In addition, residential demand (RD) charges have been emerging in residential tariff designs mainly in the US and also some preliminary tests have been done within 
Europe. These RD charges include a fee which is based on the customer's highest demand (expressed in $\mathrm{kW}$ ) over a certain period of time. Most of these rates combine-aside from a fixed fee-electricity charges based on (peak) load [ $€ / \mathrm{kW}]$ with charges based on energy consumed $[€ / \mathrm{kWh}]$ which in turn can alter by the time-of-use [8]. As different combinations are possible (e.g., TOU tariff combined with RD charges), the key attributes which characterize the different dynamic pricing schemes have to be defined first (cf. Figure 1) to be able to assess the effectiveness of these schemes.

\begin{tabular}{|c|c|c|}
\hline $\begin{array}{l}\text { Rationale } \\
\text {-Time of use } \\
\text { •Load level }\end{array}$ & $\begin{array}{l}\text { Cost components } \\
\text {-Generation } \\
\text {-Transmission \& distribution } \\
\text { - Retail } \\
\text { - Other charges }\end{array}$ & $\begin{array}{l}\text { Cost drivers } \\
\text { •Power } \\
\text { •Energy } \\
\text { •Independent of power and } \\
\text { energy }\end{array}$ \\
\hline $\begin{array}{l}\text { Dynamics } \\
\text {-Number of time blocks } \\
\text {-Price update frequency } \\
\text {-Price spread }\end{array}$ & $\begin{array}{l}\text { Events } \\
\text {-Duration } \\
\text {-Occurence } \\
\text {-Price spread }\end{array}$ & $\begin{array}{l}\text { Active Demand } \\
\text {-Manual } \\
\text {-Automated }\end{array}$ \\
\hline
\end{tabular}

Figure 1. Attributes of electricity pricing schemes (adapted from Dütschke and Paetz, 2013 [7]; and Dupont et al., 2014 [9]).

The basic rationale behind dynamic pricing is that the energy price varies by time of use and/or by the current load at household level [7]. Different cost components can be distinguished in energy pricing reflecting the value chain of energy, i.e., generation, transmission and distribution and retail. Moreover, different cost drivers can be distinguished for a given component: costs driven by energy usage $[€ / \mathrm{kWh}]$, by (peak) power $[€ / \mathrm{kW}]$ or which are independent of these factors, e.g., $[€ / \#$ end users]. An example of the latter is the metering cost which is partly driven by the number of end users connected [9]. The underlying costs of the generation and transmission and distribution business largely depend on the energy usage and the (peak) power, whereas the costs associated with retail are typically driven by the number of end users [9]. Both the generation and the transmission and distribution components are thus candidates to be made dynamic and this can be done according to the energy usage $[€ / \mathrm{kWh}]$ and/or the (peak) power [ $€ / \mathrm{kW}]$ component [1]. The dynamics of a pricing scheme can be expressed by the number of time blocks per day in which the rate can vary, the price update frequency and the price spread, i.e., price differentials between time blocks. In addition to these characteristics, also extraordinary events can be introduced by introducing lower priced periods (e.g., in periods with abundant renewable power generation) or higher priced periods (e.g., in periods with peak demand). Consumers can be stimulated to avoid using energy in periods with peak demand by using critical peak pricing (CPP) or critical peak rebates (CPR). In the latter case consumers receive a rebate if their consumption is below a given threshold during the critical peak period. These events are defined by their duration (e.g., one hour), their average occurrence (e.g., ten times a year) and the price spread (price differentials between events and non-events rates). Finally, end users enrolled in price-based DR programs may respond to price signals in a manual or automated way. Examples of automated response devices are smart thermostats and always-on gateway systems that automatically turn off appliances such as air-conditioning units or freezers during periods of high prices within the limit of comfort settings determined by the end users, or start flexible loads such as washing machines or tumble dryers during periods of low prices taking into account the final deadline defined by the end user.

\subsection{Literature Review on Household Response to Dynamic Pricing Schemes}

The effectiveness of DR programs depends critically on the nature of the system where they are implemented [10]. Relevant factors include climate (e.g., presence or absence of air-conditioning units), 
built environment (e.g., average insulation level of buildings), appliance ownership (e.g., penetration of various white good appliances), supply mix (e.g., penetration of renewable energy generation), regulatory requirements (e.g., in terms of tariff structures allowed), attitudes to data privacy (e.g., ownership of data readings from smart meters), socio-economic variables (e.g., income, education, size of households, etc.), other attitudes (e.g., towards the environment or individual financial gains) and timing and practical execution of everyday practices (e.g., doing the laundry, washing dishes, entertainment, etc.) $[5,11]$. The variety of factors in play makes it extremely difficult to predict the effectiveness of a given DR program. What can be stated in terms of statistically significant correlations relevant to different system contexts is limited and intuitively obvious. The results of the ADVANCED project (http://www.advancedfp7.eu/), which builds on a database containing meta-analyses of 138 active demand pilots, serve well to prove this point. The ADVANCED consortium found out that households with higher electricity consumption tend to achieve greater overall electricity demand reduction-a rather commonsense result, because they have more scope for doing so [12]. Other findings are that homeowners are more likely to reduce energy demand than households renting their place; that households with automated electric water heaters will respond better to incentives to use more energy for a while (the boiler can heat the water up to the upper temperature setting when electricity prices are low); and that older people are more likely to shift loads in time (probably because they spend more time at home). No statistically significant correlations between other socio-economic factors such as household income or education and response to price signals could be found by the ADVANCED consortium, while Faruqui and Sergici [13] did find a correlation between average education level and load shifting. We can therefore conclude that careful contextual and transdisciplinary research and understanding, building on the insights and practices of local stakeholders and households, is needed to make a specific DR program a success [14]. However, there is also a need to transcend the single-case perspective and to stimulate learning across projects. The aim of the present survey paper is to contribute to this mutual learning, by assessing prospects for residential DR from the standpoint of the end users. To do so, we first present the findings of some meta-reviews on the effects of DR programs (for more details, see the S3C project Deliverable 1.1 [15]). The results are summarized here under the headings of four guiding hypotheses in the field of end-user response to dynamic pricing schemes. These hypotheses refer to the attributes 'Dynamics', 'Events' and 'Automation vs. manual response' (cf. Figure 1), which are most apparent from the end-user point of view. The survey of the case research reported in Section 4 then looks for a validation or refutation of these hypotheses based on empirical findings.

H1: In order to stimulate load shifting, the number of time blocks of electricity pricing schemes should be limited and prices should not be updated too frequently.

Dynamic pricing rates should be easy for the customer to understand $[6,16]$. If the customer does not understand how the pricing scheme works or is overburdened with information, they will not be able to respond appropriately to the price signals manually. Following this simplicity requirement, each day should be divided into a limited number of time blocks when designing a dynamic tariff. Moreover, if the scheme alludes at changing the routine behavior of the end user, prices should not be updated too frequently, but remain the same and thus predictable over a reasonable amount of time. Survey results reported in Dütschke and Paetz [8] showed that end users were more likely to enroll in pricing programs where prices are fixed for a longer period. Furthermore, the responsiveness of participants increases when the change in tariff is announced timely (e.g., a day rather than an hour in advance) [10]. On the other hand, depending on the project goal, it might for example be needed to include seasonal effects or even shorter term effects. In case the end user is being supported by a reliable automated energy system in translating the price signals into actions, more dynamic and complex tariff arrangements with higher update frequencies become feasible (cf. infra) $[1,13]$. However, the understandability of the pricing scheme is still required, as the user has to be willing to give the control over appliances to the new energy management set-ups and understanding is an important prerequisite to engagement in a DR program [17]. 
H2: The response of end users to extraordinary events will be better when they are announced timely and are limited in duration.

By definition, extraordinary events occur rarely, e.g., only a few times a year. The responsiveness of participants increases when the occurrence of an event is announced timely (e.g., day-ahead) [7]. In addition, a shorter period makes it easier for end users to shift load $[5,11,18]$. These findings are in line with Strengers [19], who argues from a practice-based perspective that relatively short (e.g., up to four hours) and properly announced critical peak-pricing events allow households to re-arrange their daily routines in response to this price signal by e.g., undertaking alternative practices, shifting peak-time practices (e.g., doing the laundry) to other times of the day, and/or leaving the house.

H3: In order to convince end users to change their energy end-use behavior, price spreads should be considerable.

In order to give a strong price signal to end users, the price spread should be large $[6,16]$. According to Stromback et al. [4], end users react more to changes in price than to the actual price of electricity. A comparison across trials reported in [18] confirms this statement. Faruqui and Sergici [13] refer to an "arc of price responsiveness", meaning that the amount of demand response indeed rises with the peak to off-peak price ratio but at a decreasing rate. Field test results reported in [7] also showed a preference for higher price spreads focusing more on the chance to save money as long as there was a cap on the highest price zone. Darby and McKenna [5] however indicate that consumers, because of their greater familiarity with flat rates, are more willing to participate in programs with smaller spreads and thus minimizing their financial risk. These findings of course do not need to be contradictory. In general, end users that are not enrolled in a dynamic pricing scheme yet might be risk averse and prefer a low spread, while end users that are subject to dynamic tariffs with larger spreads have more incentives to shift consumptions and thus exhibit stronger reactions to price signals.

H4: For complex and/or unpredictable pricing schemes automatic control should be applied in order to increase the load shifting by end users.

Households enrolled in price-based programs may respond to price signals in a manual or automated way. Research indicates that consumers are not keen on changing daily routines, so they seem to be more in favor of automated DR than manual control [7]. Moreover, end users cannot be expected to be continually monitoring a price signal and react accordingly. Therefore some kind of automation is needed when complex tariff designs are applied [20]. Hence, there appears to be considerable potential for deploying enabling technologies to foster greater price response [6,21]. This is also backed by the results reported in [4] showing that applying automated control to smart appliances that can react to outside information leads to considerably higher end-user response for TOU and critical peak tariffs. Faruqui and Sergici [13] indicate that for a given price ratio experiments with enabling technologies_-including besides automation also in-house displays (IHDs) and ambient displays - tend to produce larger peak reductions and display more price-responsiveness. Moreover, consumers subject to RD charges which vary by time of use and (peak) load can lower their electricity bill by a) avoiding simultaneous use of appliances to lower their peak load and b) shifting energy usage away from more expensive to less expensive hours. As this adds to the complexity, enabling technologies could assist consumers when demand charges are applied. Further piloting and research is however needed to validate this [8]. It thus appears that for complex and/or unpredictable tariff structures, automatic control is a better fit. In this case, the simplicity requirements are less stringent although the end user should still be able to understand the tariff. However, Stromback et al. [4] (p. 67) also stress the need for consumer education (broadly defined) even when using automated devices. These authors found that 92 trials using a static TOU without any accompanying end-user education gave an average $1 \%$ rise in overall consumption and a $4 \%$ fall in peak usage, whereas 122 trials that included some education led to $4 \%$ overall and $6 \%$ peak reduction. 


\section{Case Study Methodology}

Next, we attempted to test whether these hypotheses were confirmed or contradicted by recent experiences in European smart grid pilot projects. Sorell [22] sets out the guidelines for systematic reviews in the field of research related to energy policy. They involve:

- A clear specification of the research questions to be addressed;

- Systematic and exhaustive searching of available literature;

- Applying explicit criteria for inclusion or exclusion of studies or cases;

- Appraising the quality of the included studies/cases using transparent criteria;

- Summarizing and synthesizing the results in an objective manner.

Bullet points one and two of Sorell's list are addressed in the previous section in the form of a set of key hypotheses on the effectiveness of dynamic pricing schemes. The following sub sections describe each of the bullets three to five in more detail.

\subsection{Application of Explicit Criteria for Inclusion or Exclusion of Studies or Cases}

For the purpose of the S3C project, we were specifically looking for the most interesting and promising smart grid projects with learning potentials from the point of view of end-user engagement. The selected projects form the so-called S3C "Family of Projects" (FoP). The identification and selection of projects to form the FoP has been based on two different pillars:

- Selection of projects in two already existing databases, with the rationale to capture at least those projects that are already known in the research community:

- the JRC-Petten database on smart grid projects in Europe, which is currently under the analysis of the Grid+ project (coordinated by RSE, one of the S3C partners), and

- the list of demonstration projects that has been built within the "Member States Initiative: A pathway towards EEGI functional projects" within the European Electricity Grid Initiative (EEGI);

- A selection of projects proposed by each S3C project partner, mostly on a national and local level, with the rationale to additionally capture those projects that might be less widely known, but with a particularly innovative character.

Based on these two sources, a long list of potential candidate projects for inclusion in the S3C project was drafted. Consequently, the list was thoroughly screened using an extensive set of selection criteria (for more details, see the S3C project Deliverable 2.1 [23]). The most important inclusion criteria used were:

- Does the project have a central focus on end-user engagement?

- Does the project include actual field experiments?

- Are all data available for analysis in S3C and are there no restraints on the use of these data?

In the end 32 smart grid projects that fulfilled all three criteria were found willing to share their experiences with the S3C project consortium. This number compares well to the 55 European smart grid projects with a focus on consumer engagement identified by Gangale et al. [24] using the JRC database, with 38 projects found willing to answer a questionnaire. For the purposes of this paper, only those projects that have implemented or are currently implementing dynamic pricing schemes are considered (13 in total). Out of these projects, only those that had concluded testing and already performed an evaluation at the time of writing have been considered ( 9 in total). The Table A1 in Appendix gives an overview of these projects and the type of dynamic tariffs they used. Project results relevant to the different hypotheses are discussed in Section 4. 
Even if the number of case studies on which this paper is based is limited, they still represent the result of a search based on the use of the JRC and EEGI inventories, which can be considered the most comprehensive and updated inventories of smart grid projects in Europe to date. Given the qualitative nature of our research (cf. Section 3.2) and the small sample size, serious limitations of course exist with respect to the generalizability of the empirical results. The aim of our research, however, is not to make a comprehensive assessment of household responses to dynamic tariffs, but instead to explore, document and discuss different types of response witnessed today in a number of experimental set-ups.

\subsection{Quality Appraisal of Included Cases Using Explicit Criteria}

The qualitative case studies conducted in S3C provide insights in how each member of the FoP deals with end-user engagement, including specific experiences with dynamic pricing schemes. The case study methodology was based on a triangular data collection, extracted from project documentation and interviews with project representatives and/or implementers. In some case studies these sources were complemented with (group) interviews with end-user participants in the project and/or interviews with stakeholders involved in implementation and/or monitoring. Each case study was performed by the S3C consortium partner who established contact with the respective smart grid project, based on a predefined case study format (on file with the authors). To assure high quality and consistency standards, each case study was thoroughly reviewed by another consortium partner. In addition, factual project information on the end-user interaction schemes used by each case study was entered into an online database.

\subsection{Summary of Results in an Objective Manner}

In the process of drawing conclusions we were faced with a number of difficulties. First, as mentioned in Section 2.2, a full understanding of household reactions to DR interventions requires an in-depth contextual understanding, especially of the energy-related practices (washing, drying, heating, air conditioning, bathing, cooking) these households are engaged in. Since we had to rely on the research done and reported by the smart grid pilots themselves, this detailed information was not available to us. Secondly, as many projects applied multiple incentives combined with several other interventions, such as project communication, the appropriate type of end-user feedback, and so forth, it was difficult to single out the effect of introducing dynamic tariffs. Third, due to the diversity of projects that were investigated-in terms of project design, scope, scale, timeframes, objectives and target groups-it is also difficult to compare them on equal footing in the cross-case analysis.

In view of these difficulties, a staged research method was used to draw cross-cutting lessons from the individual cases. First, a thematic analysis of cause-impact relations was conducted to formulate tentative answers on the hypotheses. To this end, data packages relevant to the different hypotheses were assembled from the case study reports, drawn from the respective sections in the case study template. Next, a cross-case analysis was carried out to identify interdependences, contradictions and congruencies among the outcomes of the thematic analyses and to assess cross-cutting cause-impact relations, success factors and pitfalls w.r.t. end-user engagement. In order to identify successful interventions and to clarify the reasoning based on which success factors, pitfalls and best practices have been attributed, the qualitative data analysis process was based on the Toulmin Model of Argumentation [25]. Toulmin's model enables to rigorously think about backings, warrants and countervailing factors for recommendations, thus making the argumentation and findings solid.

For each intervention that was found in the case studies, a claim (thesis) was made explicit, followed by the warrants (supporting statements), backings for these warrants and the rebuttals (counter-arguments) deriving from the case study data. The outcomes of these research steps were integrated into a synthesis of results and generic conclusions from the cross case-analysis (for more details, see the S3C project Deliverable 3.4 [26]). The results of this reconstruction are next discussed in Section 4 . 


\section{Results}

This section compares the results of the in-depth analysis of the S3C case studies with the findings from literature starting from the four hypotheses introduced in Section 2.2. Tables 1-4 summarize our findings from the selected projects on the four hypotheses.

H1: In order to stimulate load shifting, the number of time blocks of electricity pricing schemes should be limited and prices should not be updated too frequently.

Table 1. Summary of findings from projects for Hypothesis 1.

\begin{tabular}{|c|c|c|}
\hline Project Name & Demand Response Incentive & Observed Results \\
\hline AlpEnergy & $\begin{array}{l}\text { Choice between: } \\
\text { - } \quad \text { Static TOU tariff: } 2 \text { price levels/day; } \\
5 \mathrm{ct} / \mathrm{kWh} \text { spread; updated } 1 \text { time } \\
\text { per year } \\
\text { - } \quad \text { Dynamic TOU tariff: } 5 \text { price levels/day; } \\
5 \mathrm{ct} / \mathrm{kWh} \text { max. spread; updated every } \\
36 \mathrm{~h}\end{array}$ & $\begin{array}{l}\text { Static TOU tariff: } 2 \% \text { average load shift } \\
\text { Dynamic TOU tariff: } 1 \% \text { average load shif } \\
90 \% \text { satisfaction with static TOU tariff }\end{array}$ \\
\hline E-DeMa & $\begin{array}{l}\text { Possibility to switch tariff arrangement on } \\
\text { a monthly basis } \\
\text { Choice between } 7 \text { different options, ranging } \\
\text { from static TOU tariff (with } 2 \text { price } \\
\text { levels/day) to dynamic RTP tariffs }\end{array}$ & $\begin{array}{l}\text { Highest level of satisfaction for static TOU } \\
\text { tariff (updated monthly) } \\
3.6 \% \text { average load shift }\end{array}$ \\
\hline TOU tariff in Italy & $\begin{array}{l}\text { Introduction of static TOU tariff: } 2 \text { price } \\
\text { levels/day; } 2 \mathrm{ct} / \mathrm{kWh} \text { max. spread, updated } \\
4 \text { times per year }\end{array}$ & $1 \%$ average load shift \\
\hline CLNR & $\begin{array}{l}\text { Static TOU tariff: } 3 \text { price levels/day, } \\
20 \mathrm{ct} / \mathrm{kWh} \text { max. spread, updated } 1 \text { time } \\
\text { per year }\end{array}$ & $\begin{array}{l}14 \% \text { reduction of consumption during } \\
\text { peak hours }\end{array}$ \\
\hline Sala-Heby & $\begin{array}{l}\text { Power-based TOU tariff: variable distribution } \\
\text { charge during peak hours ( } 7 \text { a.m.- } 7 \text { p.m.); } \\
\text { no distribution charge during off-peak hours; } \\
\text { updated } 1 \text { time per year }\end{array}$ & $\begin{array}{l}8.7 \% \text { average load shift (summer) } \\
1.6 \% \text { average load shift (winter) }\end{array}$ \\
\hline
\end{tabular}

This hypothesis has received strong support from the analysis of one of the projects in the S3C FoP, the Allgaeu trial site of the AlpEnergy project in Germany. The AlpEnergy project team developed two different tariff arrangements, both of which are TOU tariffs, but with different levels of complexity. The static pricing model consisted of two price levels (price spread of $5 \mathrm{ct} / \mathrm{kWh}$ ), distributed over the day in two time zones that remained the same between October and March and then changed in April. Essentially, the cheap price level during lunch and early afternoon hours reflected the abundant generation from solar panels in the region. The target was to sensitize the end users to the fluctuating feed-in of electricity from the solar panels into the grid. The results of this project imply that a more dynamic tariff is by no means a guarantee for higher load shifting and that the acceptance for less complex tariffs with an easy-to-understand rationale is higher than for a complex arrangement [27]. Within this tariff arrangement, the end users (70 households in total) succeeded in shifting $2 \%$ of their consumption into the lower-priced zone manually, since they did not receive an automated energy management system to support their efforts. Instead, they had access to a web portal, where they could receive information on their tariff and their consumption, and were sent a monthly informative bill. At the same time, the project tested the so-called dynamic pricing model with 30 households. This is also a TOU tariff, but consists of a more flexible and complex structure. The price spread between highest and lowest prices remained the same $(5 \mathrm{ct} / \mathrm{kWh})$. However, the dynamic pricing scheme consisted of five pricing levels which were distributed over five time blocks throughout the day. The distribution of the time blocks furthermore changed on a 36-hour basis. The changes were 
announced day-ahead on the web portal. This customer group also received a smart home starter kit to allow for automated control of two or three household appliances to support them in shifting their loads while decreasing the perceived loss of comfort by the participants. Yet, in spite of the support through the smart sockets, the 30 households testing the dynamic pricing model only succeeded in shifting $1 \%$ of their overall consumption into the lower-priced time blocks of the day. Surveys throughout the field test and after its conclusion revealed that $90 \%$ of the end users billed in the more static pricing model considered the price spread to be sufficient and stated that the feedback instruments were adequate in delivering the necessary information to perform the load shifting activities [27]. They praised the understandable structure and rationale of the tariff, which they could easily relate to the region's vast solar energy potential. The end users billed in the more dynamic pricing model however criticized the complex structure as being too difficult to translate into action. More than a third of the dynamic customers never registered to the web portal and thus, in fact, never received the price information upon which they could have based their consumption decisions [27].

Further supporting evidence for this thesis can be found in the results of the E-DeMa trial, another smart grid trial from Germany. Given the choice to switch their tariff arrangement on a monthly basis, most of the end users showed an interest in trying different solutions, but a clear tendency to eventually opt for a relatively static and easy-to-understand TOU tariff could be deduced. The seven different options that were available each month included easy and complex TOU tariffs, RTP tariffs, options for tariff events and consumption-oriented tariffs as well as a contracting option that directly linked end users and aggregators [28]. A majority of the end users eventually preferred the relatively easy and static TOU structure that consists of two price levels (with a price spread between $10 \mathrm{ct} / \mathrm{kWh}$ and $20 \mathrm{ct} / \mathrm{kWh}$, updated monthly based on European Energy Exchange prices) and two time blocks. The distribution of the two time blocks (expensive tariff zone between 7 a.m. and 9 p.m., cheap tariff zone between 9 p.m. and 7 a.m.) remained stable, so that it was easy for the end users to adapt their behavior. Very active participants achieved load shifts of up to $8.7 \%$ from the expensive to the less expensive zone. On average, the incentives could trigger a load shift of about 3.6\% [28]. One of the main conclusions drawn by the project is that a tariff product should consist of a maximum of five time blocks in order to avoid an overly complex structure that is not accepted by the end users. Furthermore, end users cannot be expected to change their behavioral patterns too often. If the distribution of price levels over the day changes too often, there is an increased risk of frustrating end users that just learned to adapt their consumption to one tariff structure and have to reconsider the management of energy-related practices in their household yet again [28].

Similar results were found in other projects within the S3C FoP. For instance, the TOU tariff applied to all households in Italy is a very simple tariff structure consisting of two time blocks per day and with quarterly price updates. This was a positive factor from the end users' point of view, and about $60 \%$ of the households involved indicated that they had shifted at least some of their consumption from the more expensive peak hours to cheaper off-peak hours. This resulted in a shift of $1 \%$ of total energy consumption from peak to off-peak hours with respect to the period prior to the introduction of the TOU tariff [29]. The CLNR project (Customer Led Network Revolution) in England also opted for a simple tariff scheme: a three-rate TOU tariff which is updated once a year. Preliminary field trial results showed that the average half-hourly energy use reduced by $14 \%$ during the peak period (between 4 p.m. and 8 p.m.), suggesting considerable behavioral change in energy end use [30].

Within the Sala-Heby project in Sweden, the distribution system operator introduced a power-based TOU distribution tariff to 200 households in their distribution area. Before the introduction of the new tariff, the end users had a conventional distribution tariff with an annual fixed access charge depending on the fuse size and a variable distribution charge (rate per $\mathrm{kWh}$ ). The new tariff included a fixed access charge depending on fuse size and a variable distribution charge calculated as the average of the five highest meter readings in peak hours (rate per $\mathrm{kW}$ ), which can be seen as a Residential Demand (RD) charge. Peak hours were set to weekdays between 7 a.m. and 7 p.m., and remaining hours are referred to as off-peak. In off-peak hours, electricity distribution is free 
of charge. The level of the power-based tariff during peak hours varied between summer $(2.57 € / \mathrm{kW})$ and winter $(8.54 € / \mathrm{kW})$ season in 2007-2008. The applied distribution tariff thus has two time blocks and is updated once a year. Project results show that there has been a consistent change of behavior after the power-based tariffs were introduced: the absolute shift from peak to off-peak and vice versa was distributed between the summer (8.7\%) and the winter (1.6\%) season [31]. A follow-up study found that during the six year period following the first study (2009-2014), households responded to the price signals by reducing individual peak demand by $9.3 \%$ (summer) and $7.5 \%$ (winter) as well as shifting electricity consumption from peak to off-peak hours by 2.4 and $0.2 \%$ respectively in the summer and winter seasons [32]. Although residential consumers are not used to being charged based on power instead of energy and most participants even indicated that they had not bothered to understand in detail the consequences of the power-based tariff, they were satisfied with noting that it is better for their private economy to use electricity in off-peak periods, supporting this first hypothesis.

H2: The response of end users to extraordinary events will be better when they are announced timely and are limited in duration.

Table 2. Summary of findings from projects for Hypothesis 2.

\begin{tabular}{lll}
\hline Project Name & Demand Response Incentive & Observed Results \\
\hline \multirow{3}{*}{ eTelligence } & Static TOU tariff: 2 price levels $/$ day; & $20 \%$ reduction of electricity \\
& $26.7 \mathrm{ct} / \mathrm{kWh}$ price spread & consumption during malus events \\
& Bonus $(0 \mathrm{ct} / \mathrm{kWh})$ and malus $(120 \mathrm{ct} / \mathrm{kWh})$ & $30 \%$ increase of electricity \\
& events based on availability of wind power & consumption during bonus events \\
\hline
\end{tabular}

Results recently published by the German smart grid project eTelligence suggest a high potential for events (notification 1 day ahead, duration 2-4 h), not only in terms of load shifting, but also in rendering the participation in smart grid projects fun and thus creating new habits that facilitate the adaption of short-notice price changes. The so-called 'Event Tariff' developed by the project team consisted of a TOU basic tariff with two price levels (with a price spread of $26.12 \mathrm{ct} / \mathrm{kWh}$ ) that are distributed in two time blocks on weekdays. During the weekend the end users were only billed in the less expensive tariff zone. In addition, so-called 'bonus' events $(0 \mathrm{ct} / \mathrm{kWh})$ and 'malus' events $(120 \mathrm{ct} / \mathrm{kWh})$ occurred based on the availability of renewable energy in the local grid [33]: these events were announced day-ahead. The field test took place in Cuxhaven close to the North Sea, where the regional energy mix is characterized by a high share of onshore and offshore wind generation. In fact, on particularly windy days the regional grid is overburdened by excess generation from the wind plants whereas on less windy days, electricity has to be bought in from elsewhere. The events served to sensitize the end users to these consequences of the local energy mix and in fact were successful at doing so. The end users used up to $20 \%$ less electricity during malus events and up to $30 \%$ more during bonus events. Results suggest that in case of bonus events, the $30 \%$ increase of load does not only originate from shifting the time-of-use, but also derives from more consumption due to the low price. End users taking part in the field trial for instance planned short-notice neighborhood parties with activities with high energy consumption when a bonus event was announced, thus showing their creativity in making positive use of the price incentive. This in turn increased the overall acceptance of the innovative tariff scheme. This approach could be mixed with an overall community approach, in which tariff events are consistently linked to competitions and community events to facilitate the reaction to the price signals for the consumers [33].

H3: In order to convince end users to change their energy end-use behavior, price spreads should be considerable. 
Table 3. Summary of findings from projects for Hypothesis 3.

\begin{tabular}{lll}
\hline Project Name & Demand Response Incentive & Observed Results \\
\hline \multirow{3}{*}{ eTelligence } & Static TOU tariff: 2 price levels/day; & 20\% reduction of electricity consumption \\
& $26.7 \mathrm{ct} / \mathrm{kWh}$ price spread & during malus events \\
& Bonus $(0 \mathrm{ct} / \mathrm{kWh})$ and malus $(120 \mathrm{ct} / \mathrm{kWh})$ & $30 \%$ increase of electricity consumption \\
& events based on availability of wind power & during bonus events \\
\hline
\end{tabular}

\begin{tabular}{|c|c|c|}
\hline AlpEnergy & $\begin{array}{l}\text { Choice between: } \\
\text { - } \quad \text { Static TOU tariff: } 2 \text { price levels/day; } \\
5 \mathrm{ct} / \mathrm{kWh} \text { spread; updated } 1 \text { time } \\
\text { per year } \\
\text { - } \quad \text { yynamic TOU tariff: } 5 \text { price } \\
\text { levels } / \text { day; } 5 \mathrm{ct} / \mathrm{kWh} \text { max. spread; } \\
\text { updated every } 36 \mathrm{~h}\end{array}$ & $\begin{array}{l}\text { Static TOU tariff: } 2 \% \text { average load shift } \\
\text { Dynamic TOU tariff: } 1 \% \text { average load shift }\end{array}$ \\
\hline MoMa & $\begin{array}{l}\text { Fully flexible RTP tariff: } 31 \text { price levels; } \\
7.75 \mathrm{ct} / \mathrm{kWh} \text { max. price spread } \\
\text { Automated response }\end{array}$ & Price elasticity: -0.106 \\
\hline
\end{tabular}

The empirical findings present conflicting evidence as to whether or not high price spreads are a key to changing energy end-use behavior. Relatively large price spreads as e.g., the events in the eTelligence projects $(0 \mathrm{ct} / \mathrm{kWh}$ on a bonus event and up to $120 \mathrm{ct} / \mathrm{kWh}$ on a malus event, cf. supra) triggered the most substantial load shifting in the project sample surveyed for this article $(-20 \%$ in case of a malus event and $+30 \%$ in case of bonus events, cf. supra). This evidence suggests not only that high price spreads lead to strong reactions, but also that more consumption is easier to implement for end users than less consumption [33]. On the other hand, the hypothesis can be attenuated based on the experience from the AlpEnergy project. A lesson that could be drawn from this trial is that in case a tariff is fairly easy and allows the end users to only once adapt their behavior or only a few times throughout the life cycle of the project, a limited price spread is fully acceptable, leading however to limited load shifting $[27,34]$.

One of the goals of the project "Model City Mannheim" (MoMa) was to determine the price elasticity of energy consumption. The RTP tariff implemented in their final phase was fully flexible and allowed for a calculation of the price elasticity of the consumption of the field test customers. The overall price spread between the 31 price levels was set at $7.75 \mathrm{ct} / \mathrm{kWh}$ and the distribution of the hourly time blocks and prices was changed on a daily basis and announced a day ahead. The project calculated a significant price elasticity of -0.106 on average-i.e., if the price of electricity was raised by $100 \%$, the end users reacted with a decrease of consumption by $10.6 \%$ on average. However, it needs to be stressed that the price incentives did not reflect the currently available price spreads within given energy markets and regulatory frameworks [35].

While the meta reviews cited in Section 2.2 indicate that financial incentives should be high enough to result in actual gains to justify the loss of comfort or convenience associated with behavioral change, other end-user engagement options (besides or on top of the financial incentives) that attenuate other losses can be considered. For example, a gamification approach can be adopted, rendering the engagement in a smart grid project fun by enabling a permanent sense of achievement and feeling of membership in a club. Given that even the successful group in the AlpEnergy trial only managed to shift $2 \%$ of their energy end use [27], experimenting with other incentives that do not only rely on financial benefits appears to be an imperative.

H4: For complex and/or unpredictable pricing schemes automatic control should be applied in order to increase the responsiveness of end users. 
Table 4. Summary of project findings for Hypothesis 4 .

\begin{tabular}{|c|c|c|}
\hline Project Name & Demand Response Incentive & Observed Results \\
\hline E-DeMa & $\begin{array}{l}\text { Possibility to switch tariff arrangement on } \\
\text { a monthly basis } \\
\text { Choice between } 7 \text { different options, ranging } \\
\text { from static TOU tariff (with } 2 \text { price } \\
\text { levels/day) to dynamic RTP tariffs } \\
\text { supported by automation }\end{array}$ & $\begin{array}{l}3 \% \text { average load shift for both manual } \\
\text { and automated solutions }\end{array}$ \\
\hline Linear & $\begin{array}{l}\text { Dynamic TOU tariff: } 6 \text { price levels / day; } \\
\text { updated daily } \\
2 \text { different reward schemes: } \\
\text { - } \quad \text { Saving on electricity bill by manually } \\
\text { shifting energy use } \\
\text { - } \quad \begin{array}{l}\text { Reward for providing hours of } \\
\text { flexibility with automated } \\
\text { smart appliances }\end{array}\end{array}$ & $\begin{array}{l}\text { Response fatigue in case of manual } \\
\text { control and feedback } \\
\text { Providing hours of flexibility by smart } \\
\text { appliances realizes larger and more } \\
\text { predictable demand shifts }\end{array}$ \\
\hline MoMa & $\begin{array}{l}\text { Fully flexible RTP tariff: } 31 \text { price levels; } \\
7.75 \mathrm{ct} / \mathrm{kWh} \text { max. price spread } \\
\text { Automated response }\end{array}$ & Price elasticity: -0.106 \\
\hline
\end{tabular}

Automation does not only ease the burden on the consumer in reacting to complex and ever changing price signals, it might also serve to increase the overall flexibility of residential consumers. The AlpEnergy project and several other smart grid trials have identified the problem that in case end users are supposed to react manually to price signals, load shifting or energy saving requires first their presence at home, and second a willingness to consciously consider demand response options, which takes time [27,34]. An automated energy management system can tackle these issues. However, there is a risk that end users will not think outside the box of the energy management system, thus restricting the load shifting to its parameters only and ignoring other options, which will limit the optimal usage of the tariffs. Ideas on how to change energy practices such as mowing the lawn a few days earlier, recharging all accumulators, inviting neighbors to a spontaneous party, etc. (all witnessed in the context of the eTelligence trials [33]) cannot be triggered by smart automation software. Furthermore, the manual control schemes can be seen as a first step of a learning process to increase the acceptance of smart end-use solutions. In fact, manual options should not be neglected and automated schemes should not be preferred per se.

The aforementioned E-DeMa project for instance succeeded in successfully implementing automation, but the project results show that the difference between manual and automated load shifting potential is limited at this point in time. The project tested both options in a comparably stable technical environment with little technical difficulties. However, the differences in load shifting potential for the two end user groups were not significant and both set at around 3\%. Active consumers shifting their loads manually achieved better results than many passive customers with energy management systems. This finding underlines the fact that automated solutions requires active end-user acceptance based on the conscious examinations of settings and consumption preferences. However, as technology becomes more reliable and arising options are easier to grasp for customers, the situation could change [28].

The Belgian project Linear has tested a tariff scheme which is quite dynamic (tariff scheme with 6 time blocks and a daily update of tariffs based on Belpex day-ahead market prices and predicted generation of wind power and photovoltaics) [36]. Within this project it was decided to implement two different reward systems: one test group had the possibility to save on their electricity bill by manually shifting electricity according to the TOU tariff, while the other test group was remunerated according to the numbers of hours of flexibility provided by their smart appliances. The results show 
that both reward systems induce a change in energy consumption. However, a lot of response fatigue was observed in case of manual control and feedback of the test group with manual control clearly indicated that the pricing scheme was too complex to shift consumption manually. End users that were part of the test group with automated control of their white goods (dishwasher, washing machine and tumble dryer) and domestic hot water buffers realized larger and more predictable demand shifts [37].

In case new technical components are applied that are still of prototype character, a friendly-user test phase should be a precursor to the large scale rollout in order to avoid the aforementioned problems. This message was well-understood by the Energy@Home project (which is set in Italy and uses the TOU tariff applied to all households there) where they opted for technology which was not only easy to install and to be used by end users, but also compatible with devices that were already used in the households. This way, the automation allowed a deep integration of the system with end users' daily routines without much effort, which in turn determined the positive outcome of the project [38].

Based on the experience of MoMa that proved a high price elasticity in spite of yet unstable technological set-ups, and E-DeMa that could not prove a strong difference between manual and automated load shifting, a new hypothesis can be added: Automation in itself is not the key to successful load management [28]. Automation coupled with a learning process, in which the end users are continuously supported in case they need further feedback, is the key to success [28]. This points to a conclusion that has also been drawn in Lewis et al. [39]: the change of energy practices is a process, in which the end users have to discover their new options step by step and need to be guided through their decision making on which kind of energy practice changes can be accepted and which cannot.

\section{Discussion}

Recent research has stressed the importance of looking at residential demand response from a social practice theory point of view $[13,18]$. Looking at energy-related behavior through the lens of social practices enables an analysis of behaviors at different levels of consciousness, ranging from habitual to conscious and one-shot behavior. Energy-related practices (like washing, cooking, heating, etc.) can typically be considered habitual. However, behaviors aiming for a change of practices-like deciding whether to engage in a DR program and/or to buy smart appliances-are rather conscious or even one-shot. The process of end-user engagement in DR programs and their consequent interaction with new technologies, feedback and pricing schemes can be interpreted as a continuous change process. At the start of the process, it is assumed that end users carry out their energy-related practices in a rather habitual manner. As end users become engaged in a DR program, they are stimulated towards more conscious decision-making. This phase can be considered rather disruptive, as existing practices need to be reconsidered and redefined. In this activation phase, end-user interaction is targeted typically at achieving active end-user participation and an explicit consideration of old and new practices. As new practices are adopted, behavior becomes again more habitual. In the continuation phase, end-user interaction is then more aimed at supporting and reinforcing the new energy practices. The next sections summarize our findings on activating and continuing new behaviors in interaction with DR programs (Sections 5.1 and 5.2), while Section 5.3 discusses the limitations of our research.

\subsection{Activating Behavioral Change with Dynamic Pricing}

Based upon existing literature and an analysis of current smart grid projects, this paper has established that dynamic pricing schemes indeed activate behavioral changes in households, provided some rules of thumb are taken into account. Figures 2-5 summarize our findings on the four hypotheses. 


\section{FACTS/DATA}

- In the AlpEnergy project, a static pricing model consisting of two price levels per day (with price levels changed only once per year) resulted in a load shift of $2 \%$; whereas

- A more flexible and complex pricing model (consisting of five price levels per day, changed on a 36-hour basis) only succeeded in shifting $1 \%$ of the total load;

- In the CLNR project, a simple three-rate TOU tariff, updated once per year, managed to reduce energy use in the peak period (between $4 \mathrm{pm}-8 \mathrm{pm}$ ) by $14 \%$;

- In Italy, the introduction of a simple TOU In Italy, the introduction of a simple tou shift of $1 \%$ of total energy consumption.

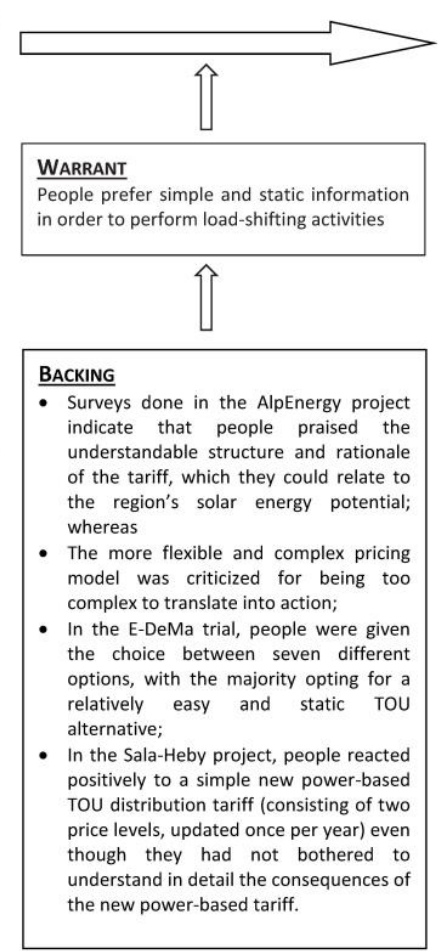

More load shifting can be achieved by dynamic tariffs if

- The number of time blocks per day is limited (max. 5 as a 'rule of thumb'); and

- Price levels for the different time blocks are kept constant for longer periods of time (max one update per month as a 'rule of thumb').

No countervailing evidence found.

Figure 2. Toulmin argumentation scheme for Hypothesis 1.

FACTS/DATA
The eTelligence project used 'bonus' events
(with electricity prices of Oct/kWh) and 'malus'
events (with electricity prices of $120 \mathrm{ct} / \mathrm{kWh}$ )
announced day-ahead. This resulted in a $20 \%$
decrease of energy use during 'malus' events
and a 30\% increase of energy use during
'bonus' events

and a $30 \%$ increase of energy use during

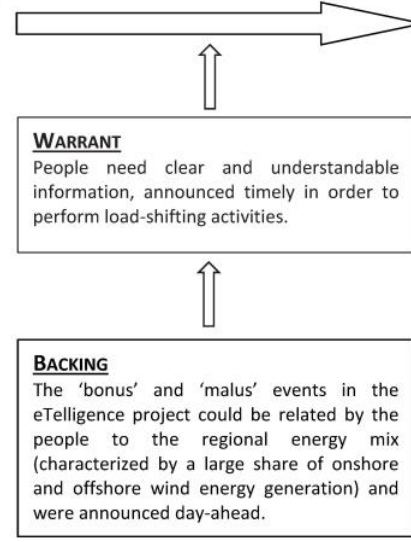

\section{LIKELY CONCLUSION}

The response of end users to events will be better when they are announced timely and when they are limited in duration.

VARRAN

People need clear and understandable to

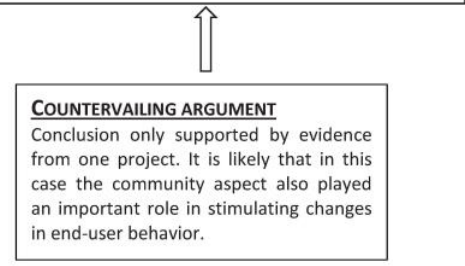

Figure 3. Toulmin argumentation scheme for Hypothesis 2.

\begin{tabular}{l}
\hline FACTS/DATA \\
- Large price spreads triggered the most \\
substantial load shifting in the sample \\
examined. The eTelligence project used \\
'bonus' events (with electricity prices of \\
Oct/kWh) and 'malus' events (with \\
electricity prices of $120 \mathrm{ct} / \mathrm{kWh}$ ) announced \\
day-ahead. This resulted in a $20 \%$ decrease \\
of energy use during 'malus' events and a \\
$30 \%$ increase of energy use during 'bonus' \\
events. \\
The MoMa project, using a RTP tariff, found \\
a quite significant price elasticity of flexible \\
demand of $-0,106$ on average (i.e. a price \\
increase of $100 \%$ will lead to $10,6 \%$ \\
demand reduction on average. \\
- In the AlpEnergy project, a limited price \\
spread led to limited load shifting.
\end{tabular}
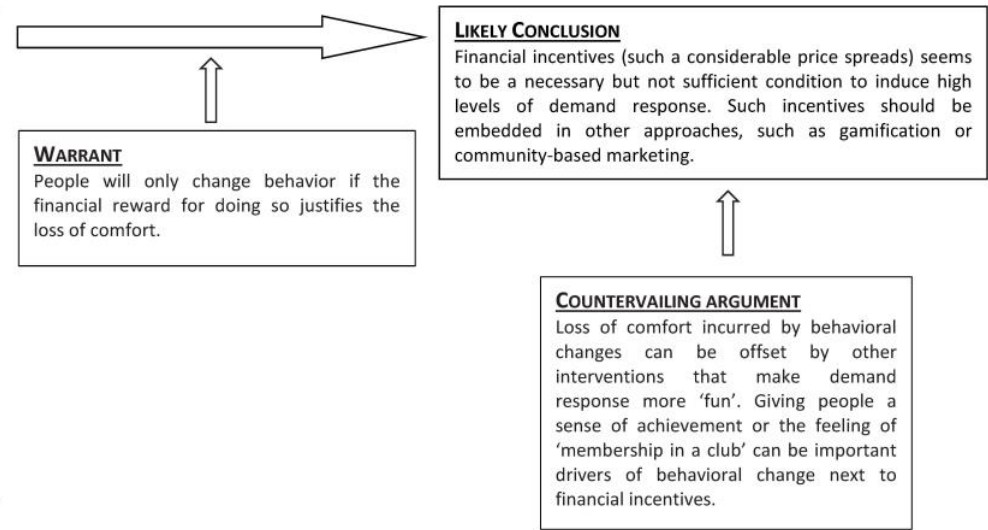

Figure 4. Toulmin argumentation scheme for Hypothesis 3. 

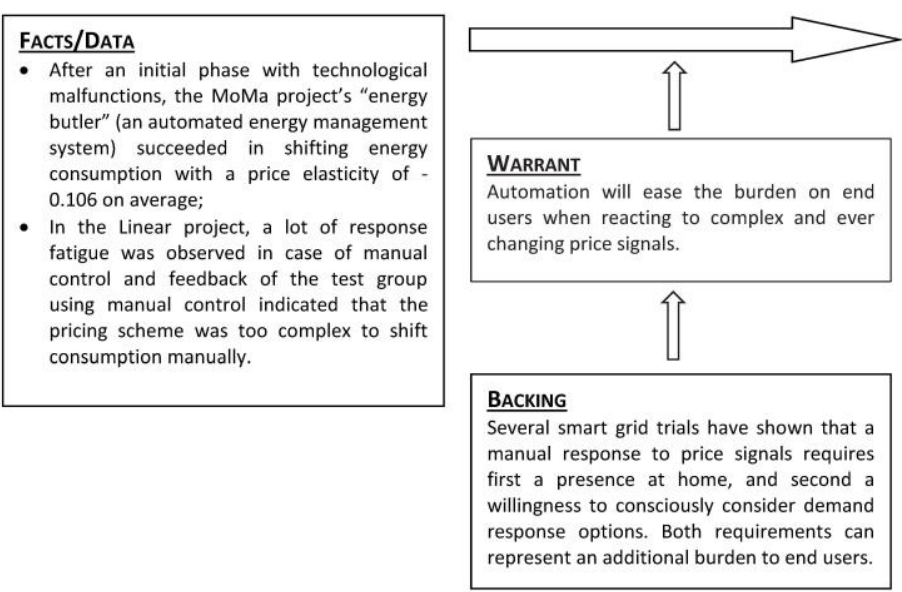

LIKELY CONCLUSION

Automatic control of appliances should be applied for complex and/or unpredictable pricing schemes in order to increase demand response by end users. Automation should however be coupled to a learning process, in which the end users are continuously supported in case they need further feedback.

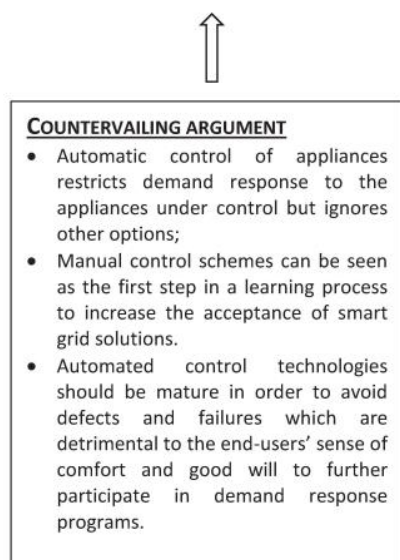

Figure 5. Toulmin argumentation scheme for Hypothesis 4.

In order to work effectively, the dynamic tariff should be simple to understand for the end users, with timely notifications of price changes, a considerable effect on their energy bill and, if the tariff is more complex, the burden for the consumer could be eased by introducing automated control. Although sometimes the mere introduction of a dynamic tariff has proven to be effective, often the success of the pricing scheme depends also on other factors influencing the behavior of end users. An important condition to make dynamic tariffs work is that the end users should be engaged with them. This can happen through a change in energy-related practices in the case of more static tariff schemes, but also by offering adequate information or mature enabling technology (e.g., in-home displays or automated devices) if the tariff structure is more dynamic. With regard to the potential of offering automated devices (e.g., as part of a new dynamic pricing 'package') as a means to 'activate' end users, there is some generally positive evidence available. For instance, Fell et al. [40] found out that a representative sample of the British population actually prefers direct load control of appliances (allowing electricity suppliers to cycle people's heating on and off for short periods in return for a lower flat rate cost per unit) over static or dynamic TOU tariffs, both with and without automated control. These findings suggest that the idea of fully-automated direct load control of appliances is acceptable in principle to many people, provided that it is operated within tightly defined bounds (in this case, only a variation of $1^{\circ} \mathrm{C}$ around a set temperature was allowed) and with an override option. Qualitative research reported in [41] also show that energy customers show a generally favourable attitude towards home energy automation and smart appliances, because of the expected ease of use and the potential to maintain householder comfort. Since automated solutions are intended to be integrated in household energy practices, this interaction should fit the needs, wishes and capabilities of the end users. The acceptance of automation/remote control will therefore in general be different for different household practices/appliances. Appliances such as freezers, electric boilers, heat pumps or electric vehicles are due to their high power and energy usage not only a very interesting 'target' for a DR program; they moreover likely show the greatest potential for automation (because their energy usage happens 'behind the back' of the end users, e.g., with an electric car, the end user can specify by when the car should be recharged, but he/she is not interested when-within the time period specified-the charging actually occurs). In addition, people may change their appreciation-changing from an initially hesitant attitude to a more enthusiastic one or changing from enthusiasm to weariness with a particular technology. In the Linear project, the test group using automated appliances reported 
no loss of comfort when using the smart appliances and remained enthusiastic throughout the project, while the test group manually reacting to a TOU tariff reacted in a 'disappointed' way (cf. Section 4, Hypothesis 4). Hence, provided that the experiences of the 'early adopters' of automated devices in combination with dynamic tariffs turn out to be positive, these experiences can be used as a 'lever' - by word-of-mouth or other normative social influences [42]—-to enroll other households in DR programs.

\subsection{Persistence of Behavioral Change in Interaction with Dynamic Pricing}

Especially in cases in which price incentives have to be translated into action manually, the risk exists that households over time revert to old practices. Accordingly the change in behavior reverses to a certain degree. However, results from different projects suggest that in most cases, the change in behavior is conserved to a certain extent over the duration of the field trial, even if a "fatigue effect" sets in [13]. The automatic implementation of dynamic pricing through energy management system can decrease the risk effect of the fatigue effect. In the Linear project, it was clearly shown that end users which were part of the test group with automated control of their white goods (dishwasher, washing machine and tumble dryer) and domestic hot water buffers realized larger and more predictable demand shifts, while the end users manually responding to the TOU incentives showed a large degree of response fatigue. However, in case technology is still in its infancy and unreliable, energy management solutions can actually cause or increase the fatigue effect, as end users engaged in trials become frustrated [43]. In order to keep end users engaged and actively participating in the project on the long term, it is important to make them feel they are doing something important. Other ways to stimulate interest need to be considered, e.g., comparison with other end users. In the Energy@Home project for example, the end-users' interest curve in the project started to go down some months after the start of the project. To stimulate the interest of the participants, a personalized newsletter (containing a graph comparing the end-user's weekly consumption with the weekly average) was introduced. This seemed to be successful in regaining the end-user's interest, as it resulted in a further decrease in end-users' consumption [38].

In the E-DeMa project, different behavioral patterns regarding the fatigue effect could be described for different types of end users. Based on their performance throughout the field test, the end users were categorized as passive (monthly savings below $3.9 \%$ of the usual energy bill) and active (monthly savings of more than $3.9 \%$ of the usual energy bill) [28]. While the active participants maintained a high engagement throughout the field trial and performed steady load shifting and/or savings, the passive end users started to lose interest after a few months and decreased their efforts. Based on data from the field tests and a questionnaire that included information on the socio-economic background of the participants, the research team discovered a correlation between education and the status of a participant. The higher their education, the more likely the end users were active end users [28]. Furthermore, active customers in the field trial were likely to live in household situations without children and in a situation in which one or more of the participants did not work or only worked part-time. This leads to a hypothesis on the influence of social practices on the performance and flexibility exhibited by households in smart grid trials. The free time available to act on the incentives and to look into the new possibilities provided by the innovative technologies is crucial for the performance in a field trial. Households with children and stronger routines have more difficulties adjusting their consumption, as their habits and daily agendas are more constrained than those of households without children. Furthermore, the test sample of the MoMa and the Linear project underlines the finding that the smart grid is currently an elite, early-adopter topic. Highly educated, richer than average home owners were clearly over-represented in the test households participating in these projects [35].

\subsection{Limitations of the Research}

It is important to note that in the projects that were studied a combination of monetary (including dynamic tariffs) and non-monetary incentives are offered to the participants, e.g., new smart appliances 
or bonus points that can be gained from energy saving games. This makes it hard to single out the effect of the dynamic pricing scheme. Another potential limitation to the generalization of the results of this paper is that smart grid project set-ups are very heterogeneous. Just as technological standardization and ensuring interoperability of different smart grid components are the key to developing market ready smart grid products, standardization of processes and research designs in the end-user activation and engagement will become the necessary prerequisite to gain scalable and replicable insights into end-user behavior, which are crucially needed to develop an acceptance and, thus, demand for the new technologies on the European markets. Since (a) nearly every demonstration project devises its own research formats based on different baseline calculations; (b) nearly all of them work with unrepresentative test samples; (c) the incentive combination and communication strategies connected with dynamic pricing schemes are unlimitedly diverse and (d) many factors influencing end-user behavior remain unknown, the results of smart grids projects can hardly be compared at this point. Up to date, similarities and differences can be pointed out and different hypotheses can be drawn. However, in order to gain acceptance for a potential smart meter and smart technology rollout, more research is needed that should ideally be based on a common research approach.

\section{Conclusions}

Breukers et al. [14] have pointed out that effecting a change in consumer behavior is a central part of a successful DR program. Behavioral change is something that has to be worked for, and is not going to occur automatically by introducing some form of dynamic pricing [44]. Households need to go through a learning experience, spanning the different stages of getting motivated (e.g., by offering some incentive or tapping into environmental values and attitudes), activating behavioral changes in interaction with the DR program, and continuing the newly acquired behavior. Many different factors besides the design and set-up of the dynamic tariff play a role in this process. Still, from our research some useful principles or rules of thumb related to fostering flexible energy behavior in response can be derived, such as the importance of clear, simple tariffs (at least in an early phase) and the need for end-user education, including well-designed feedback systems. From the household perspective, there is a significant difference between the relatively static and more dynamic forms of dynamic pricing. While static TOU tariffs appear less suited for energy systems with high penetration of fluctuating renewable energy sources, they nevertheless show a relatively good performance in shifting loads on a regular basis because they are easy to understand.

Automated solutions in combination with dynamic pricing require active end-user acceptance based on the conscious examinations of settings and own consumption preferences. TOU tariffs could perhaps pave the way for RTP with automated solutions by accustoming households to the time-dependent value of electricity.

The finding on the correlation between educational backgrounds and good performance in smart grid trials (cf. Section 5.2) further underlines the hypothesis that one of the success factors is to continuously support and engage the end users with the new technologies, instead of just deploying them in their homes. Currently, the benefits of becoming a smart household seem to be only tangible and understandable for highly educated households. For new smart grid trials aiming to reach large numbers of end users, it is crucial to develop strategies for different end-user segments with different preferences. The incentives have to be tailored to or developed from the perspective of the end users and their daily routines. More research on end-user segmentation and preferences regarding smart grid technologies is thus needed.

Acknowledgments: We would like to thank the European smart grid pilot projects who generously shared their experiences with us and thereby contributed to new insights on end-user engagement. The "Smart Consumer, Smart Customer, Smart Citizen" (S3C) project, upon which this paper is built, has received funding from the European Union's Seventh Programme for research, technological development and demonstration under grant agreement $\mathrm{N}^{\circ} 308765$. This funding is gratefully acknowledged. However, the sole responsibility for the content of this publication lies with the authors. It does not necessarily reflect the opinion of the European Communities. The European Commission is not responsible for any use that may be made of the information contained therein. 
Author Contributions: Each co-author contributed equally to the literature survey, the in-depth analysis of reported case studies. The corresponding author was the main responsible for drafting and revising the article. All authors contributed to the final approval of the version of the paper to be published.

Conflicts of Interest: The authors declare no conflict of interest.

\author{
Abbreviations \\ AMI Advanced Metering Infrastructure \\ DR Demand Response \\ EU European Union \\ FoP Family of Projects \\ RD Residential Demand \\ RTP Real-Time Pricing \\ SME Small and Medium-sized Enterprise \\ S3C FP7 funded research project "Smart Consumer, Smart Customer, Smart Citizen" \\ T\&D Transmission and Distribution \\ TOU Time-of-Use
}




\section{Appendix}

Table A1. Overview of selected projects based on the main attributes of implemented tariff schemes.

\begin{tabular}{|c|c|c|c|c|c|c|c|c|c|c|c|}
\hline \multicolumn{2}{|c|}{ Attributes } & $\begin{array}{c}\text { AlpEnergy I } \\
(D E)\end{array}$ & $\begin{array}{c}\text { AlpEnergy II } \\
(D E)\end{array}$ & CLNR (UK) & $\begin{array}{c}E-D e M a \\
(B a s i s)(D E)\end{array}$ & $\begin{array}{l}\text { Tou Tariff in } \\
\text { Italy (IT) }\end{array}$ & $\begin{array}{c}\text { Energy@Home } \\
\text { (IT) }\end{array}$ & $\begin{array}{c}\text { E-Telligence Event } \\
\text { Tariff (DE) }\end{array}$ & MOMA (DE) & Linear (BE) & $\begin{array}{l}\text { Sala-Heby } \\
\text { Energi (SE) }\end{array}$ \\
\hline \multicolumn{2}{|l|}{ Timing } & \multicolumn{2}{|c|}{ 2010-2011 } & 2011-2014 & 2011-2012 & 2009-2012 & $2011-2013$ & 2010-2011 & 2012 & 2011-2014 & 2008-2014 \\
\hline \multicolumn{2}{|l|}{ Sample size } & $\begin{array}{c}70 \\
\text { households }\end{array}$ & $\begin{array}{c}30 \\
\text { households }\end{array}$ & $\begin{array}{c} \pm 14000 \\
\text { households and } \\
\text { businesses }\end{array}$ & $\begin{array}{c}700 \text { in } \\
\text { Mühlheim + } \\
400 \text { in Krefeld }\end{array}$ & $\begin{array}{c} \pm 28000 \\
\text { households }\end{array}$ & 50 households & 650 & 670 & $\begin{array}{l}240 \text { households } \\
\text { (55 with manual } \\
\text { response, } 185 \text { with } \\
\text { automated response) }\end{array}$ & $\begin{array}{c} \pm 5000 \\
\text { households }\end{array}$ \\
\hline \multicolumn{2}{|l|}{ Tariff type } & TOU & TOU & TOU & TOU & TOU & TOU & TOU & RTP & RTP & TOU \\
\hline \multicolumn{2}{|l|}{ Rationale } & Time of use & Time of use & Time of use & Time of Use & Time of use & Time of use & Time of use & Time of Use & Time of use & Load level \\
\hline \multicolumn{2}{|l|}{$\begin{array}{c}\text { Cost } \\
\text { components }\end{array}$} & $\begin{array}{l}\text { Generation } \\
\text { Distribution }\end{array}$ & $\begin{array}{l}\text { Generation } \\
\text { Distribution }\end{array}$ & $\begin{array}{l}\text { Generation } \\
\text { Distribution }\end{array}$ & $\begin{array}{l}\text { Generation } \\
\text { Distribution }\end{array}$ & $\begin{array}{l}\text { Generation } \\
\text { Distribution } \\
\text { Transmission }\end{array}$ & $\begin{array}{c}\text { Generation } \\
\text { Distribution } \\
\text { Transmission } \\
\end{array}$ & $\begin{array}{l}\text { Generation } \\
\text { Distribution }\end{array}$ & $\begin{array}{l}\text { Generation } \\
\text { Distribution }\end{array}$ & $\begin{array}{l}\text { Generation } \\
\text { Distribution }\end{array}$ & Distribution \\
\hline \multicolumn{2}{|l|}{ Cost driver } & Energy & Energy & Energy & Energy & Energy & Energy & Energy & Energy & Energy & Power \\
\hline \multirow{3}{*}{ Dynamics } & $\begin{array}{c}\text { Number of time } \\
\text { blocks /day }\end{array}$ & 2 & 5 & 3 & 2 & 2 & 2 & 2 & 24 & 6 & 2 \\
\hline & $\begin{array}{l}\text { Price update } \\
\text { frequency }\end{array}$ & Once a year & Every $36 \mathrm{~h}$ & Once a year & Monthly & $\begin{array}{c}\text { Every three } \\
\text { months }\end{array}$ & $\begin{array}{l}\text { Every three } \\
\text { months }\end{array}$ & Static & Daily & Daily & Once a year \\
\hline & Price spread & $5 \mathrm{ct} / \mathrm{kWh}$ & $5 \mathrm{ct} / \mathrm{kWh}$ & $\begin{array}{l}\text { About } 20 \mathrm{ct} / \mathrm{kWh} \\
\text { (between highest } \\
\text { and lowest price) }\end{array}$ & $\begin{array}{l}\text { Between } 10 \\
\text { and } 20 \mathrm{ct} / \mathrm{kWh}\end{array}$ & $\operatorname{Max} 2 \mathrm{ct} / \mathrm{kWh}$ & $\operatorname{Max} 2 \mathrm{ct} / \mathrm{kWh}$ & $26.12 \mathrm{ct} / \mathrm{kWh}$ & $7.75 \mathrm{ct} / \mathrm{kWh}$ & $\begin{array}{c}\text { Average daily } \\
\text { spread } 8 \mathrm{ct} / \mathrm{kWh} \\
\text { (between highest } \\
\text { and lowest price) }\end{array}$ & $\begin{array}{c}2.57 € / \mathrm{kW} \\
\text { (summer) } \\
8.54 € / \mathrm{kW} \\
\text { (winter) }\end{array}$ \\
\hline \multirow{4}{*}{ Events } & Duration & $\mathrm{N} / \mathrm{A}$ & N/A & N/A & N/A & $\mathrm{N} / \mathrm{A}$ & N/A & $2-4 \mathrm{~h}$ & N/A & N/A & N/A \\
\hline & Occurance & $\mathrm{N} / \mathrm{A}$ & N/A & N/A & $\mathrm{N} / \mathrm{A}$ & N/A & N/A & Irregular & N/A & N/A & N/A \\
\hline & Announcement & N/A & N/A & N/A & N/A & $\mathrm{N} / \mathrm{A}$ & N/A & Day-ahead & N/A & $\mathrm{N} / \mathrm{A}$ & $\mathrm{N} / \mathrm{A}$ \\
\hline & $\begin{array}{c}\text { Price level } \\
\text { during events }\end{array}$ & $\mathrm{N} / \mathrm{A}$ & $\mathrm{N} / \mathrm{A}$ & $\mathrm{N} / \mathrm{A}$ & $\mathrm{N} / \mathrm{A}$ & & N/A & $\begin{array}{l}\text { Bonus: } 0 \mathrm{ct} / \mathrm{kWh} \\
\text { Malus: } 120 \mathrm{ct} / \mathrm{kWh}\end{array}$ & N/A & N/A & N/A \\
\hline \multicolumn{2}{|l|}{$\begin{array}{c}\text { Active } \\
\text { demand }\end{array}$} & Manual & $\begin{array}{c}\text { Manual + } \\
\text { automated }\end{array}$ & Manual & $\begin{array}{c}\text { Manual + } \\
\text { automated }\end{array}$ & Manual & $\begin{array}{c}\text { Manual + } \\
\text { automated }\end{array}$ & Manual & $\begin{array}{c}\text { Manual + } \\
\text { automated }\end{array}$ & Manual + automated & Manual \\
\hline \multicolumn{2}{|l|}{$\begin{array}{l}\text { Observed } \\
\text { effects }{ }^{1,2,3}\end{array}$} & $\begin{array}{l}\text { Average load } \\
\text { shift of } 2 \%\end{array}$ & $\begin{array}{l}\text { Average load } \\
\text { shift of } 1 \%\end{array}$ & $\begin{array}{c}\text { Average } 14 \% \\
\text { reduction of } \\
\text { consumption } \\
\text { during peak time }\end{array}$ & $\begin{array}{l}\text { Average load } \\
\text { shift of } 3.6 \%\end{array}$ & $\begin{array}{l}\text { Average load } \\
\text { shift of } 1 \%\end{array}$ & $\begin{array}{c}\text { Average load } \\
\text { shift of } 2 \%-3 \%\end{array}$ & $\begin{array}{c}20 \% \text { during Malus } \\
\text { Events, } 30 \% \text { during } \\
\text { Bonus Events }\end{array}$ & $\begin{array}{c}\text { Average } \\
\text { price } \\
\text { elasticity of } \\
-0.106\end{array}$ & $\begin{array}{c}\text { N/A (results } \\
\text { reported in hours of } \\
\text { flexibility offered by } \\
\text { different appliances) }\end{array}$ & $\begin{array}{r}\text { Average load } \\
\text { shift of } 8.7 \% \\
\text { (summer) and } \\
1.6 \% \text { (winter) }\end{array}$ \\
\hline
\end{tabular}

${ }^{1}$ Average load shift is defined as the difference between the $\%$ of electricity consumption during peak periods in the DR setting compared to the \% of electricity consumption during peak periods in a reference period (e.g., the year preceding the DR test) or control group (without DR); ${ }^{2}$ Average reduction of electricity consumption during peak time is defined as difference (in \%) between average peak electricity consumption in the DR setting compared to peak electricity consumption in a reference period (e.g., the year preceding the DR test) or control group (without DR); ${ }^{3}$ Average price elasticity is defined as \% change in electricity consumption/\% change in price. For example, a price elasticity of - 0.1 means that if price were increased by $100 \%$, households on average reacted by decreasing their consumption by $10 \%$ during the set timeframe. 


\section{References}

1. Faruqui, A.; Harris, D.; Hledik, R. Unlocking the $€ 53$ billion savings from smart meters in the EU: How increasing the adoption of dynamic tariffs could make or break the EU's smart grid investment. Energy Policy 2010, 38, 6222-6231. [CrossRef]

2. Giordano, V.; Fulli, G. A business case for Smart Grid technologies: A systemic perspective. Energy Policy 2012, 40, 252-259. [CrossRef]

3. European Commission (EC). European Smart Grids Technology Platform: Vision and strategy for Europe's Electricity Networks of the Future; Report EUR 22040; Office for Offical Publications of the European Commission: Luxembourg, 2006.

4. Stromback, J.; Dromacque, C.; Yassin, M.H. Empower Demand. The Potential of Smart Meter Enabled Programs to Increase Energy and Systems Efficiency: A Mass Pilot Comparison; VaasaETT: Helsinki, Finland, 2011.

5. Darby, S.; McKenna, E. Social implications of residential demand response in cool temperate climates. Energy Policy 2012, 49, 759-769. [CrossRef]

6. Kim, J.-H.; Shcherbakova, A. Common failures of demand response. Energy 2011, 36, 873-880. [CrossRef]

7. Dütschke, E.; Paetz, A.G. Dynamic electricity pricing-Which programs do consumers prefer? Energy Policy 2013, 59, 226-234. [CrossRef]

8. Hledik, R. Rediscovering Residential Demand Charges. Electr. J. 2014, 7, 82-96. [CrossRef]

9. Dupont, B.; De Jonghe, C.; Olmos, L.; Belmans, R. Demand response with locational dynamic pricing to support the integration of renewables. Energy Policy 2014, 6, 344-354. [CrossRef]

10. Battle, C.; Rodilla, P. Electricity Demand Response Tools: Status Quo and Outstanding Issues; IIT Working Paper IIT-08-006A; Universidad Pontificia Comillas: Madrid, Spain, 2008.

11. Breukers, S.; Mourik, R. The End-Users as Starting Point for Designing Dynamic Pricing Approaches to Change Household Energy Consumption Behaviours; DuneWorks: Eindhoven, The Netherlands, 2013.

12. ADVANCED Consortium. Consolidated Report on the Key ADVANCED Conclusions. Deliverable 6.5. Available online: http:/ / www.advancedfp7.eu (accessed on 7 June 2016).

13. Faruqui, A.; Sergici, C. Household response to dynamic pricing. A survey of 15 experiments. J. Regul. Econ. 2010, 2, 193-225. [CrossRef]

14. Breukers, S.; Heiskanen, E.; Brohmann, B.; Mourik, R.M.; Feenstra, C.F.J. Connecting research to practice to improve energy demand-side management (DSM). Energy 2011, 36, 2176-2185. [CrossRef]

15. S3C Consortium. Report on State-of-the-Art and Theoretical Framework for end User Behaviour and Market Roles. S3C Project Deliverable 1.1. Available online: http:/ /www.s3c-project.eu (accessed on 1 May 2016).

16. Faruqui, A.; Hledik, R.; Sergici, S. Piloting the Smart Grid. Electr. J. 2009, 22, 55-69. [CrossRef]

17. Appelrath, H.-J.; Kagermann, H.; Mayer, C. Future Energy Grid. Migrationspfade ins Internet der Energie; Acatech Studie; Deutsche Akademie der Technikwissenschaften: Munich, Germany, 2012.

18. U.K. Department of Energy \& Climate Change (DECC). Demand Side Response in the Domestic Sector-A Literature Review of Major Trials; Department of Energy \& Climate Change: London, UK, 2012.

19. Strengers, Y. Peak electricity demand and social practice theories: Reframing the role of change agents in the energy sector. Energy Policy 2012, 44, 226-234. [CrossRef]

20. Dong Energy. The eFlex Project. Dong Energy: Virum, Sweden, 2012.

21. Electric Power Research Institute. Price Elasticity of Demand for Electricity: A Primer and Synthesis; EPRI: Palo Alto, CA, USA, 2007.

22. Sorell, S. Improving the evidence base for energy policy: The role of systematic reviews. Energy Policy 2007, 35, 1858-1871. [CrossRef]

23. S3C Consortium. Description of the Projects to form the 'Family of Projects'. S3C Project Deliverable 2.1. 2013. Available online: http:/ / www.s3c-project.eu (accessed on 1 June 2016).

24. Gangale, F.; Mengolini, A.; Onyeji, I. Consumer engagement: An insight from smart grid projects in Europe. Energy Policy 2013, 60, 621-628. [CrossRef]

25. Toulmin, S.; Janik, A.; Rieke, S. An Introduction to Reasoning, 2nd ed.; Prentice Hall: Englewood Cliffs, NJ, USA, 1986.

26. S3C Consortium. Report on Case Analyses, Success Factors and Best Practices. S3C Project Deliverable 3.4. 2013. Available online: http:/ / www.s3c-project.eu (accessed on 1 June 2016). 
27. Albrecht, C.; Karg, L.; Kleine-Hegermann, K. Fallstudie der Projektregion Allgäu; B.A.U.M. Consult GmbH and Allgäuer Überland: Munich, Germany, 2011.

28. Becher, S.; Berlitz, H.-J.; Caci, M.; Dietrich, K.; Ebert, A.; Frank, R.; Franz, O.H.; Grunwald, L.; Giese, P.; Hackbarth; et al. Verbundprojekt E-Energy: E-DeMa, Entwicklung und Demonstration Dezentral Vernetzter Energiesysteme hin Zum E-Energy Markplatz der Zukunft; RWE AG: Essen, Germany, 2013.

29. Maggiore, S.; Gallanti, M.; Grattieri, W.; Benini, M. Impact of the enforcement of a Time-of-Use tariff to Residential customers in Italy. In Proceedings of the CIRED 22nd International Conference on Electricity Distribution, Stockholm, Sweden, 10-13 June 2013.

30. British Gas. Initial Time of Use Tariff Trial Analysis; Report CLNR-L015; British Gas: London, UK, 2013.

31. Bartusch, C.; Wallin, F.; Odlare, M.; Vassileva, I.; Wester, L. Introducing a demand-based electricity distribution tariff in the residential sector: Demand response and customer perception. Energy Policy 2011, 39, 5008-5025. [CrossRef]

32. Bartusch, C.; Alvehag, K. Further exploring the potential of residential demand response programs in electricity distribution. Appl. Energy 2014, 125, 39-59. [CrossRef]

33. Agsten, M.; Bauknecht, D.; Brinker, W.; Conrads, R.; Diebels, V.; Erge, T.; Feuerhahn, S.; Heinemann, C.; Hermsnmeier, J.; et al. eTelligence Abschlussbericht. Neue Energien brauchen neues Denken; EWE AG: Oldenburg, Germany, 2012.

34. Karg, L.; Kleine-Hegermann, K. Sustainable Power Systems for the Alpine Space; Guidelines for Regional Decision Makers and Practitioners; B.A.U.M. Consult GmbH: Munich, Germany, 2011.

35. Kießling, A. Modellstadt Mannheim Abschlussbericht; Beitrag von moma zur Transformation des Energiesystems für Nachhaltigkeit, Beteiligung, Regionalität und Verbundenheit; MVV AG: Mannheim, Germany, 2013.

36. Dupont, B.; De Jonghe, C.; Kessels, K.; Belmans, R. Short-term consumer benefits of dynamic pricing. In Proceedings of the 2011 8th International Conference on the European Energy Markets conference, Zagreb, Croatia, 25-27 May 2011.

37. Belmans, R.; Beusen, B.; Boesmans, B.; Cardinaels, W.; Claessens, B.; Claessens, S.; Coomans, P.; D’hulst, R.; De Meyer, W.; Degraeve, J.; et al. Linear: Demand Response for Families. Linear Project Report. 2014. Available online: http:/ / www.linear-smartgrid.be/ (accessed on 7 June 2016).

38. Bellifemine, F.L. Analisi del valore di un sistema di Home Energy Management; Energy@home: Rome, Italy, 2013.

39. Lewis, P.E.; Dromacque, C.; Brennan, S.; Stromback, J.; Kennedy, D. Empower Demand 2, Energy Efficiency Through Information and Communication Technology—Best Practice Examples and Guidance; Vaasa ETT: Helsinki, Finland, 2012.

40. Fell, M.J.; Shipworth, D.; Huebner, G.M.; Elwell, C.A. Public acceptability of domestic demand-side response in Great Britain: The role of automation and direct load control. Energy Res. Soc. Sci. 2015, 9, 72-84. [CrossRef]

41. Paetz, A.-G.; Dutschke, E.; Fichtner, W. Smart homes as a means to sustainable energy consumption: A study of consumer perceptions. J. Consum. Policy 2012, 35, 23-41. [CrossRef]

42. Hobman, E.V.; Frederiks, E.R.; Stenner, K.; Meikle, S. Uptake and usage of cost-reflective electricity pricing: Insights from psychology and behavioural economics. Renew. Sustain. Energy Rev. 2016, 57, 455-467. [CrossRef]

43. Karg, L.; Kleine-Hegermann, K.; Wedler, M.; Jahn, C. E-Energy Abschlussbericht. Ergebnisse und Erkenntnisse aus der Evaluation der Sechs Leuchtturmprojekte; B.A.U.M. Consult GmbH: Munich, Germany, 2014; Available online: hppt:/ / www.e-energy.de (accessed on 7 June 2016).

44. Boork, M.; Thomtén, M.; Brolin, M.; Uyterlinde, M.; Straver, K.; Kraan, C.; Kleine-Hegermann, K.; Laes, E.; Valkering, P.; Maggiore, S. Key success factors and barriers to end-user engagement in smart grid projects. In Paper Presented at the 2014 BEHAVE Conference, London, UK, 2014; Available online: http://behaveconference.com/wp-content/uploads/2014/08/F_Magdalena_Boork_Technical_ Research_Institute_of_Sweden.pdf (accessed on 1 June 2016).

(C) 2016 by the authors; licensee MDPI, Basel, Switzerland. This article is an open access article distributed under the terms and conditions of the Creative Commons Attribution (CC-BY) license (http://creativecommons.org/licenses/by/4.0/). 